\title{
TEMPO GERÚNDIO: ALGUMAS REFLEXÕES POÉTICAS SOBRE O PROCESSO CRIATIVO E A CASA DA INFÂNCIA
}

\author{
TIEMPO GERÚNDIO: ALGUNAS REFLEXIONES POÉTICAS SOBRE EL \\ PROCESO CREATIVO Y LA CASA DE LA INFANCIA
}

\section{Maria Virginia Gordilho Martins}

EBA-UFBA/CAPES

\begin{abstract}
Resumo: Vivi uma infância em um sobrado no Recôncavo Baiano, através do qual germinaram jardins e muitos aprendizados que ora constituem a matéria de que sou feita, ou melhor, que em mim sempre se está fazendo, onde a arte e a vida se entrelaçam com o rememo-rar. Foi nesses primeiros passos que capturei certezas mutantes, pois o processo criativo é um tempo gerúndio. Com essas reflexões, a proposta registra o processo criativo de obras realizadas em 2017 e 2018. Germino o pensamento visual entre prática e teoria tendo como referências principais Gaston Bachelard, Henri Bergson e Cecilia Salles.
\end{abstract}

Palavras-chave: sobrado, infância, folhas, gerúndio, processo.

Resumen: Viví mi infancia en una residencia en el Reconcavo Baiano, a través de la cual germina-ran jardines y muchos conocimientos que ahora constituyen la materia de que soy hecha, o mejor, que en mi siempre se está haciendo, donde el arte y la vida se entrelazan con el rememorar. En esos primeros pasos he capturado certezas cambiantes, pues el proceso creativo es un tiempo gerundio. Con estas reflexiones, la propuesta registra el proceso creativo de obras realizadas en 2017 y 2018. Germino el pensamiento visual entre prác-tica y teoría, teniendo como principales referencias Gaston Bachelard, Henri Bergson y Cecilia Salles.

Palavras Clave: residencia, infancia, hojas, gerundio, proceso. 


\section{Algumas reflexões poéticas}

Num tempo que se faz cada vez mais próximo, rememoro, neste artigo, a infância que passei em um sobrado no Recôncavo Baiano, localizado na Rua da Linha, hoje nominada Vereador João Silva (em homenagem a meu avô materno), na cidade de Santo Antonio de Jesus.

As memórias do Recôncavo são fortes. São existenciais, autobiográficas em si mesmas, permitindo-me, por vezes, fabulações com lembranças "roubadas" de meus irmãos, facilmente contaminadas pelas histórias contadas por eles em espaços e tempos distintos, pois, ainda pequena, sendo a quarta de cinco irmãos, vivenciei um período da infância com minha avó materna, Domnina Rezende Sanches de Almeida, quando convivi intensamente com a natureza, em um sobrado de estilo eclético datado de 1912, localizado na cidade de Santo Antonio de Jesus.

Atualmente, observo que foi nessas vivências que germinou o processo artístico que venho desenvolvendo nesses últimos anos, fecundado em pomares, quintais, porões, medos, brincadeiras e muitos aprendizados que ora constituem a matéria de que sou feita, ou meIhor, que em mim sempre se está fazendo, onde arte e vida se entrelaçam com as lembranças. Parafraseando a Professora baiana Ana Luz ${ }^{1}$, registro que, nesses primeiros passos, capturei as certezas sempre provisórias e mutantes com que venho adubando o processo criativo, que se transformam em dúvidas e geram outras certezas que, seguramente, serão outras futuras dúvidas, pois o processo criativo é sempre um tempo gerúndio.

Assim, este artigo promove uma visibilidade dos documentos de percurso para a criação de

1 Que costuma usar a expressão "tempo gerúndio" para expressar a volatilidade do tempo, a impossibilidade de sua retenção e as perenes transformações que ele engendra. obras realizadas em 2017 e 2018, práticas artísticas autobiográficas nas quais recolhi algumas coisas bonitas que encontrei pelos caminhos e as acondicionei em pequenos arquivos. Desenhei plantas que germinam ou adormecem, eternizadas em vitrines, cobertas de ouro ou prata e cobre, e, por vezes, repousam sobre pequenas almofadas de veludo seladas em caixas de acrílico. Semeio matéria, memória e conceito. Germino o pensamento visual entre prática (experimentos, desenhos, e objetos) e teoria (textos de artista, anotações e leituras), como sementes que fecundam o percurso criativo, tendo como referências principais Gaston Bachelarde Didi-Huberman.

\section{A casa da infância}

O lugar, chamado de "Chácara Conceição" era povoado por gente simples, que conservava a potencialidade de transformar aquilo que se encontra ao lado da morada, no mato, à beira dos regatos: argila, areia, terra vermelha tauá, ${ }^{2}$ fumo, fibras, mandioca, sementes e muitos outros materiais.

Essa região, Recôncavo da Bahia, no entorno de Salvador, compreende uma unidade dual da fisicalidade, porto e porta portuguesa, território de taipa de pilão ${ }^{3}$. Abrigou engenhos de cana-de -açúcar desde os primórdios da colonização e atividades salineiras, nos quais se desenvolveu a cultura escrava fervilhada nas senzalas e nos trapiches. História de grandeza e de miséria para explicitar seu campo de convergência, formado por uma bipolaridade: ficção e realidade.

Acredito que, nesse sobrado e em seus arre-

\footnotetext{
2 Palavra indígena: argila aluvial colorida com hematita, óxido de ferro, excelente pigmento vermelho.

3Técnica de construção muito utilizada no período colonial, especialmente em regiões onde não existia a cal. A técnica consistia em socar a massa de terra em um pilão, em formas denominados taipais.
} 



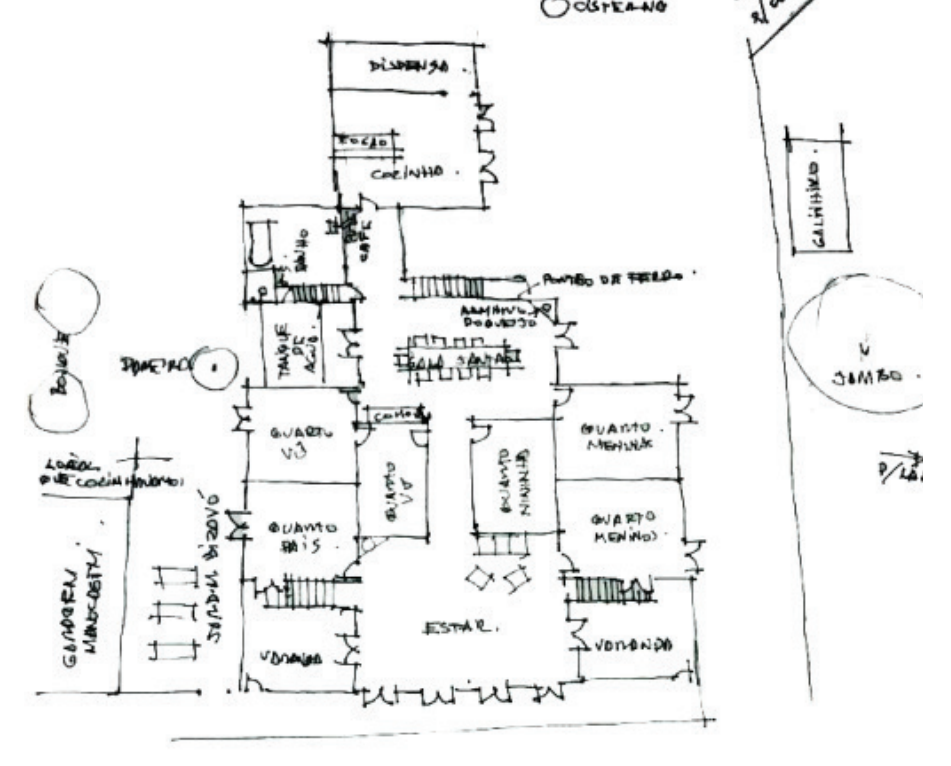

Exisos.

tulei "Coisas bonitas que encontrei pelos caminhos..." (Figura 3). Junto com ele, vieram as primeiras questões, relativas à memória e ao tempo: Qual a relação dos objetos que arquivo com a memória? Como criar obras com esses registros?

\section{O arquivo: "Coisas bonitas que encontrei pe- los caminhos..."}

Na tentativa de encontrar possíveis respostas, retomo os quatro porões da casa grande. Quando rememoro cada um, posso ainda sentir cada cheiro específico que pairava no ar, e até escutar o grito das pessoas que sempre recorriam a minha avó para entregar achados e buscar perdidos: "Dona Domnina, acho que the serve esta manga de candeeiro..." Ou: "Perdi a tampa da licoreira, a senhora consegue uma que se encaixe?" Lá se ia ela guardar a manga e buscar uma tampa exata entre centenas que estavam enroladas em papel de seda azul acondicionadas em caixas de maçã (coisa rara naquele tempo).

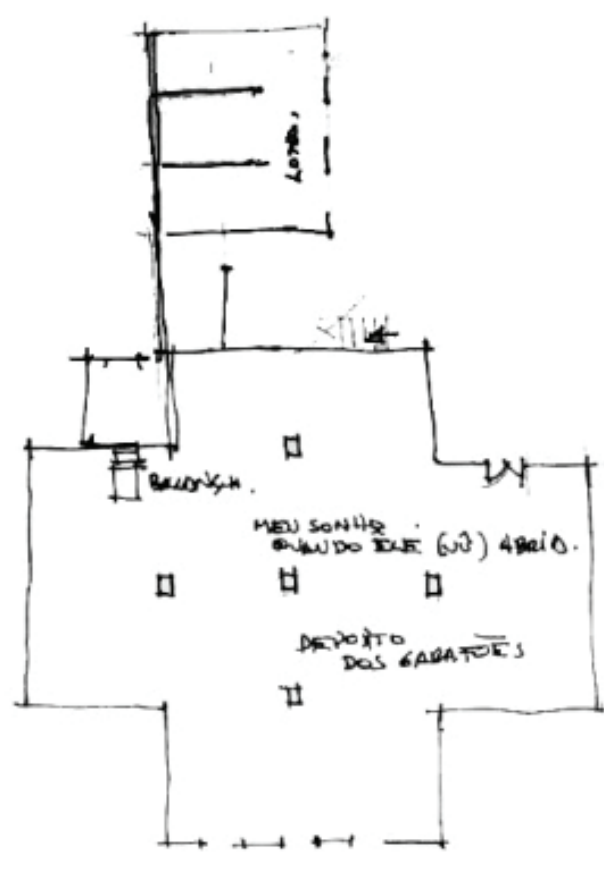

A partir dessas lembranças-imagem, na obra "Coisas bonitas que encontrei pelos caminhos" (Figura 3), referencio um fragmento do capítulo III, "Da sobrevivência das imagens, a memória e o espírito", do livro Matéria e Memória, de Henri Figura 2 - Plantas baixas desenhadas de memória por meu irmão mais velho, o arquiteto Geraldo Jose Veloso. Bergson. Aspectos relevantes sobre Lembrança pura, Lembrança imagem e Percepção muito me ajudaram a estabelecer uma melhor compreensão sobre o referido arquivo. Segundo Bergson:

Imaginar não é lembrar-se. Certamente uma lembrança, à medida que se atualiza, tende a viver numa imagem; mas a recíproca não é verdadeira, e a imagem pura e simples não me 


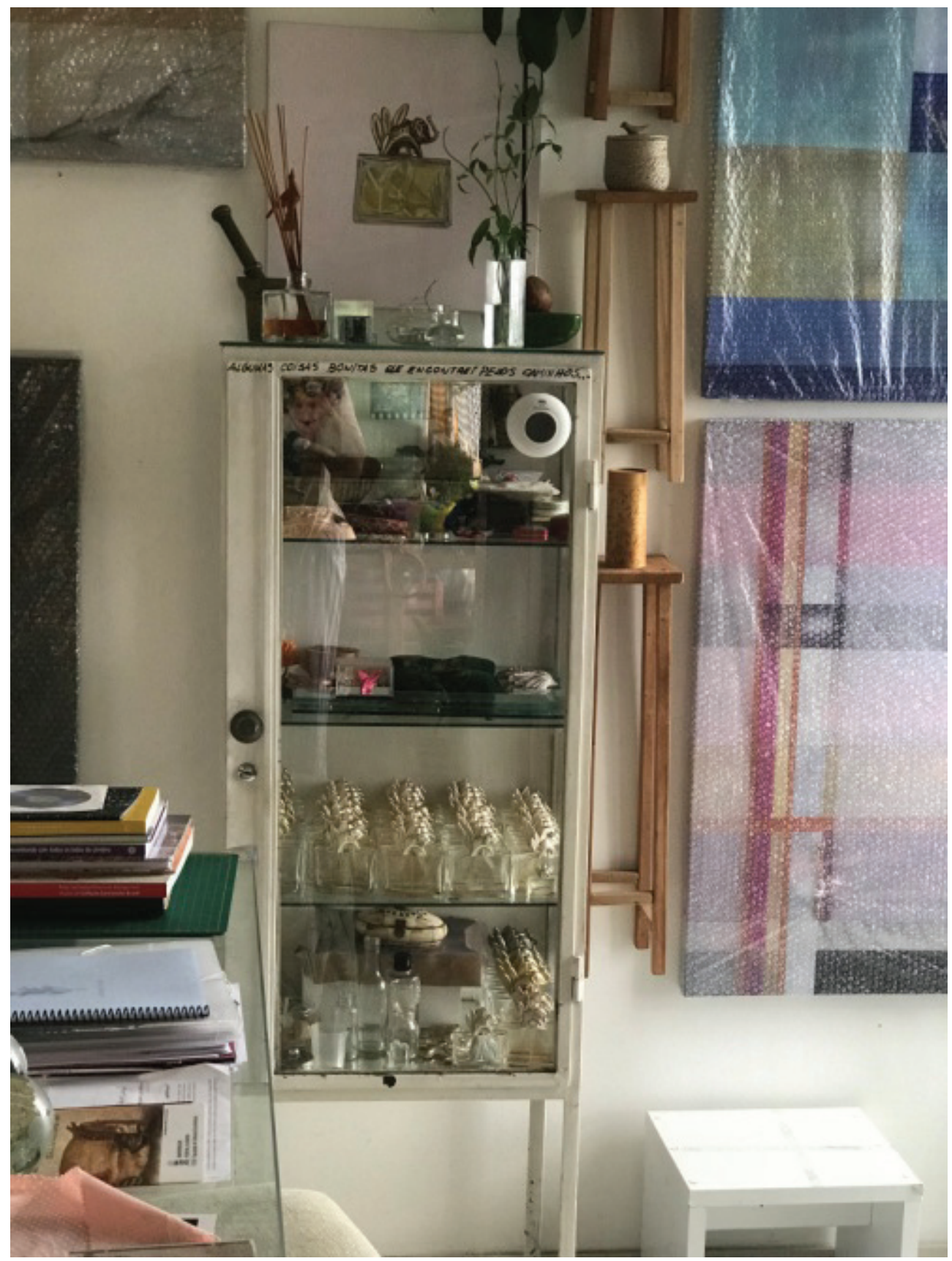

Figura 3 - "Coisas bonitas que encontrei". Vitrine de vidro 153×50×35 m. (Arquivo no atelier da autora) 
reportará ao passado a menos que seja efetivamente no passado que eu vá buscá-la, seguindo assim o progresso contínuo que a trouxe da obscuridade à luz. (BERGSON, 2010, p. 158)

Nesses "dinamismos" de passado e presente, bem como em diferentes conceitos, utilizei frascos de perfumes que venho arquivando há quase vinte anos e criei a obra "Umanada" (Figura 4), em parceria coma artista curitibana Beatriz Nocera (in memoriam).

Pude refletir, com essa obra, que o tempo mesmo sendo heterogêneo e pleno de lacunas, espacialidades distintas e saltos sociais e culturais - pode trazer uma continuidade no pensamento visual. Outra questão significativa que observei, no percurso criativo, é que, quando, na obra, entrelaçam-se matéria, memória e conceito, ela se torna uma tríade significativa para a arte contemporânea.

Assim, nesse percurso de cultivo, revisitei a sala de estar, também o quintal e as árvores frutíferas...

Retornei ao sobrado e adentrei, sentindo o cheiro de flores, angélicas, recém-colocadas em dois vasos de prata cinzelados manualmente, postos em dois pés de jacarandá, que zelavam por um pequeno corredor, conduzindo à sala de jantar.

Dessa vez, a sala estava silenciosa. Acomodeime numa das almofadas de veludo verde da cadeira conversadeira. Elas estavam lá, junto ao piano. Eram três cadeiras abraçadas. A palhinha do assento estava gasta, e os pés simulavam patas. Interpelavam a força da oralidade que desencadeia a natureza da memória de "Arquivos Vivos". Fiquei imaginando que conversas foram sussurradas naquele abraço mudo e negro de jacarandá...

Sim, essas "cadeiras conversadeiras" me encantaram... Iniciei um diálogo com elas no instante em que as vi. Imaginei como seriam significativas para uma obra, e vários conceitos povoaram minha imaginação questionadora, remetendo-me, mais uma vez, a Bachelard:
A casa é uma das maiores forças de integração para os pensamentos, as lembranças e os sonhos do homem. Nessa integração, o princípio de ligação é o devaneio. O passado, o presente e o futuro dão à casa dinamismos diferentes, dinamismos que não raro interferem às vezes se opondo, às vezes excitandose mutuamente. Na vida do homem, a casa afasta contingências, multiplica seus conselhos de continuidade. Sem ela, o homem seria um ser disperso [...]. É corpo e é alma. É o primeiro mundo do ser humano. Antes de ser 'jogado no mundo', como o professam as metafísicas apressadas, o homem é colocado no berço da casa. E sempre, nos nossos devaneios, ela é um grande berço. Uma metafísica concreta não pode deixar de lado esse fato, esse simples fato, na medida em que ele é um valor, um grande valor ao qual voltamos nos nossos devaneios. O ser é imediatamente um valor. A vida começa bem, começa fechada, protegida, agasalhada no regaço da casa. (BACHELARD, 2000, p. 26)

Busquei materiais que pudessem gerar uma amálgama interessante. Assim, recolhi partituras musicais, como ilustra a Figura 5, e juntei objetos memoráveis, desenhos, diários, e repus folhas banhadas com ouro sobre almofadas de veludo, seladas no arquivo anteriormente mencionado.

Essas "correspondências" trouxeram outras memórias, e passei a recolher folhas de árvores frutíferas, as mesmas que me alimentaram na infância: manga rosa, manga carlota, graviola, tamarindo, seriguela, pitanga, goiaba, acerola e jaca.

À medida que elas secavam, bordei cada uma com linha vermelha. A sensação era de retorno ao barro, os pés sujos de lama e a seiva que escorria como sangue das frutas arrancadas do pé.

Não tive dúvida: criei pequenas páginas em fibra de algodão, embebidas com CMC (car- 
Figura 4 - "Umanada". Objetos instalados e pintura, $40 \times 40$ $X 40 \mathrm{~cm}$. (Arquivo da autora)
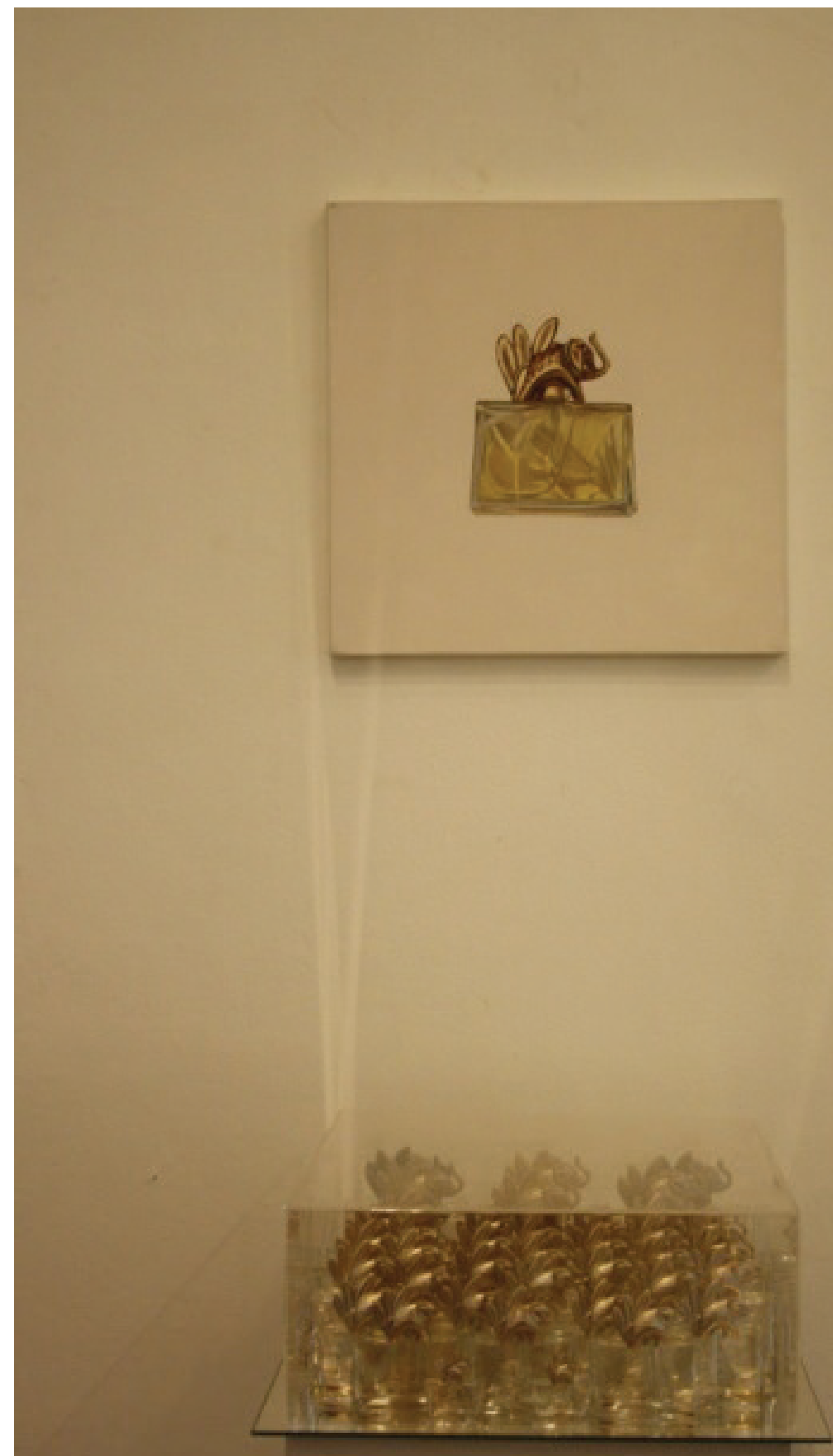


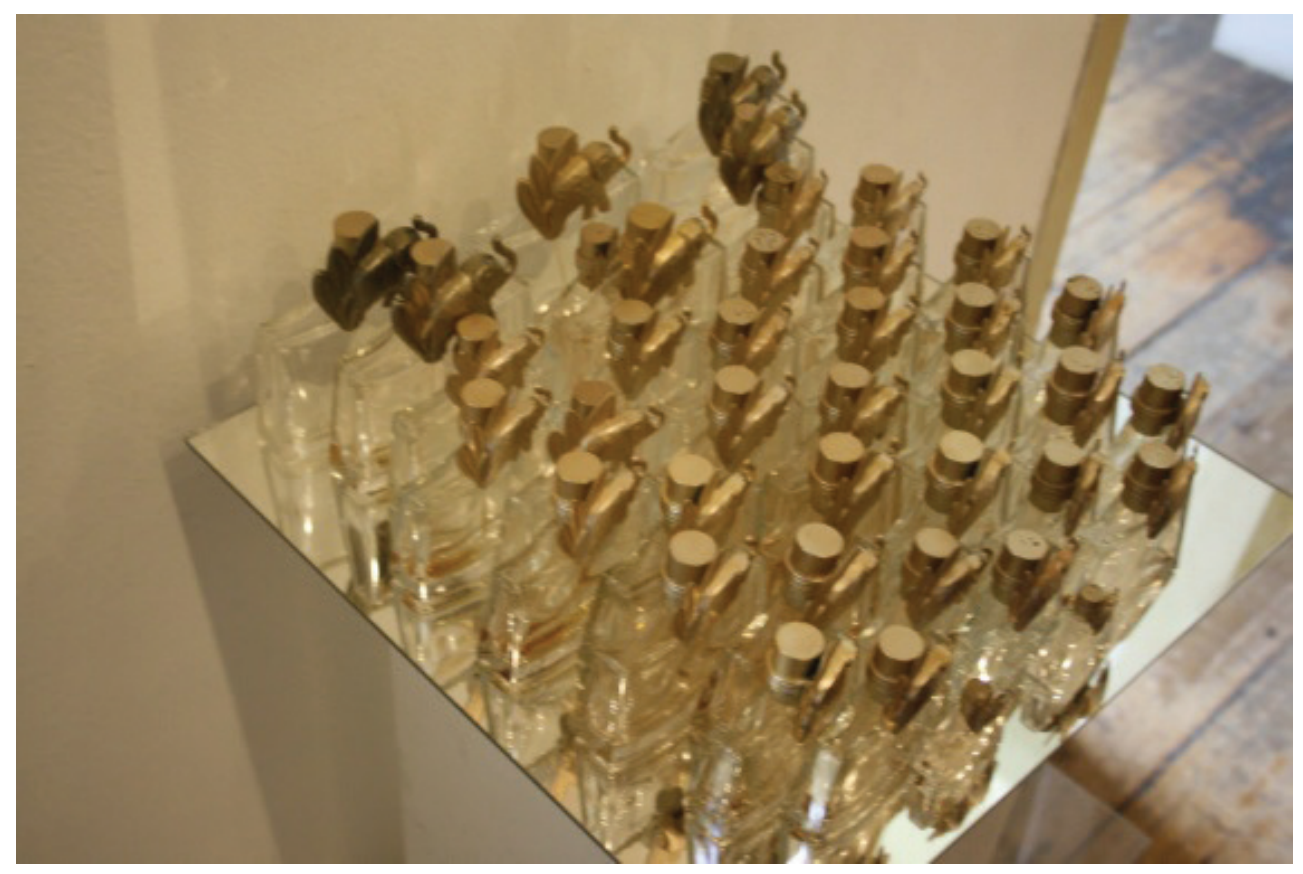
Figura 4 - "Umanada”. Objetos instalados e pintura, $40 \times 40$ $X 40 \mathrm{~cm}$. (Arquivo da autora)

box de metil celulose), e acondicionei aqueles instantes em uma pequena caixa de acrílico, formatando um livro de artista (Figura 6). Eternizei com cobre uma pequena folha de mangueira, coloquei-a na capa ou tampa, e selei como se sela um tempo leve de vivências, de frágeis intensidades e de devires fugazes. Assim, na obra "Entre folhas", recolhi e acondicionei fibras, ares e outonos do tempo em que existiam quintais floridos, com as fendas e plantas que geram.

Há, nesse livro de artista, frestas de pensamentos que me levaram até o quintal - memórias pessoais e íntimas -, lugar seminal e sagrado, onde os dias eram lentos e se estendiam até a Rua da Linha.

Percebi, com o processo de criação dessas obras, que o alcance de uma dimensão do tempo-espaço pode ser acentuado com - procedimento instaurador do trabalho, que passa pela técnica, em conjunto com a formatação de um pensamento visual por onde a memória transite em fronteiras borradas. Aqui, tempos distintos se entrecruzaram e povoaram a casa da infância com idas e vindas, tecendo outros conceitos, pois a poética não foi criada de uma só vez. Ela se potencializou no percurso, em um tempo gerúndio...

\section{Referências}

BACHELARD, Gaston. A poética do espaço. 2. Ed. São Paulo. Martins Fortes, 2008.

BERGSON, Henri. Matéria e memória: ensaio sobre a relação do corpo com o espírito.4. Ed. São Paulo: Ed. Martins, 2010

GORDILHO, Viga. Terra Homem Signo, Uma Criação Plástica com Fibras, Pigmentos e Corantes naturais Brasileiros associados a possibilidades sintéticas. Salvador, 1995. Universo Técnico, 103 p. il. e Universo Imaginário, 43p. il. Mestrado em Artes EBA/ UFBA, Salvador, 1995. 


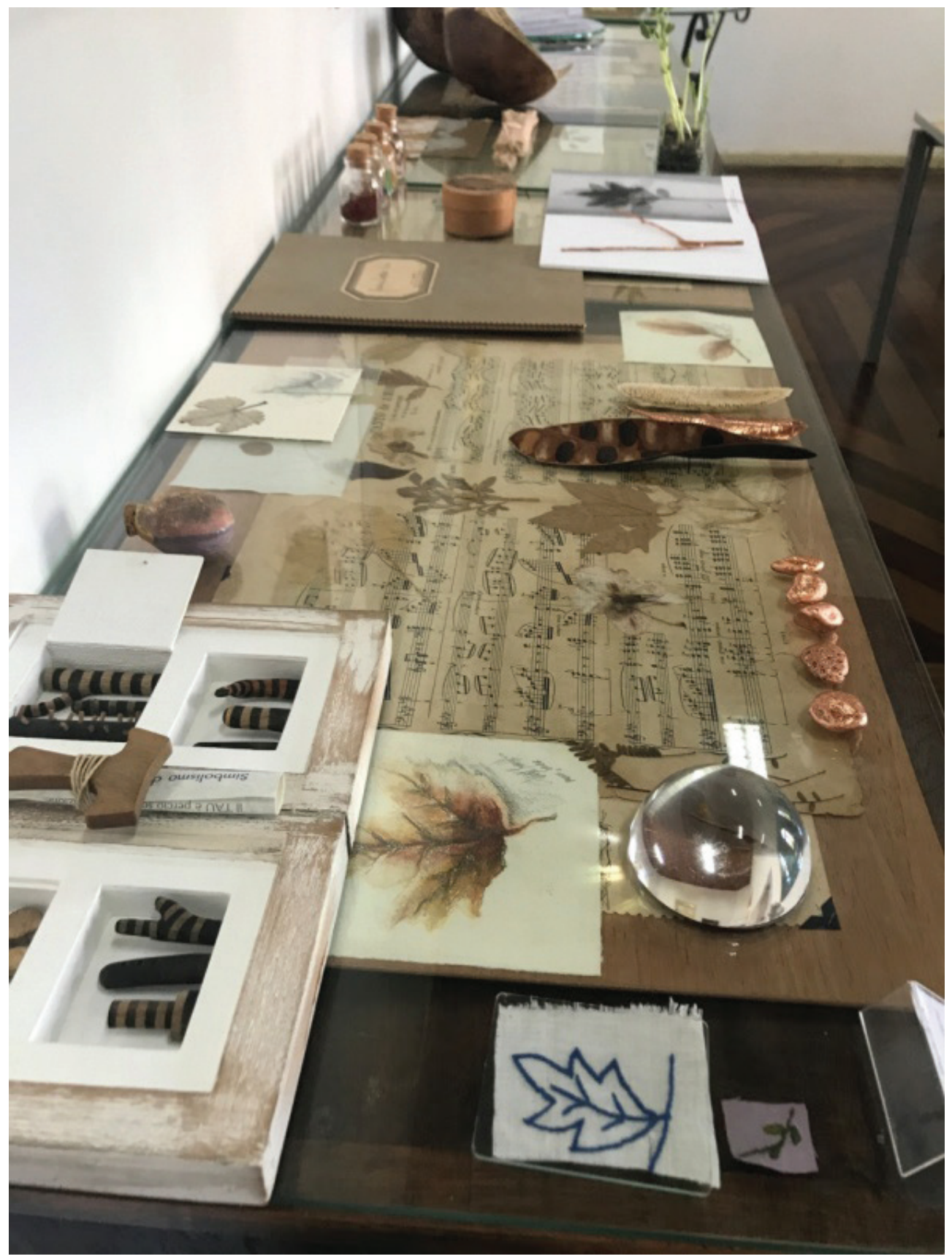

Figura 5 - "Algumas correspondências". Detalhes, partituras, palavras, vidro, desenhos, ouro, terras, veludo e objetos. Dimensões variadas. Obra apresentada na sala Riolan Coutinho, EBA - UFBA, inserida no projeto 2018. (Arquivo da autora) 


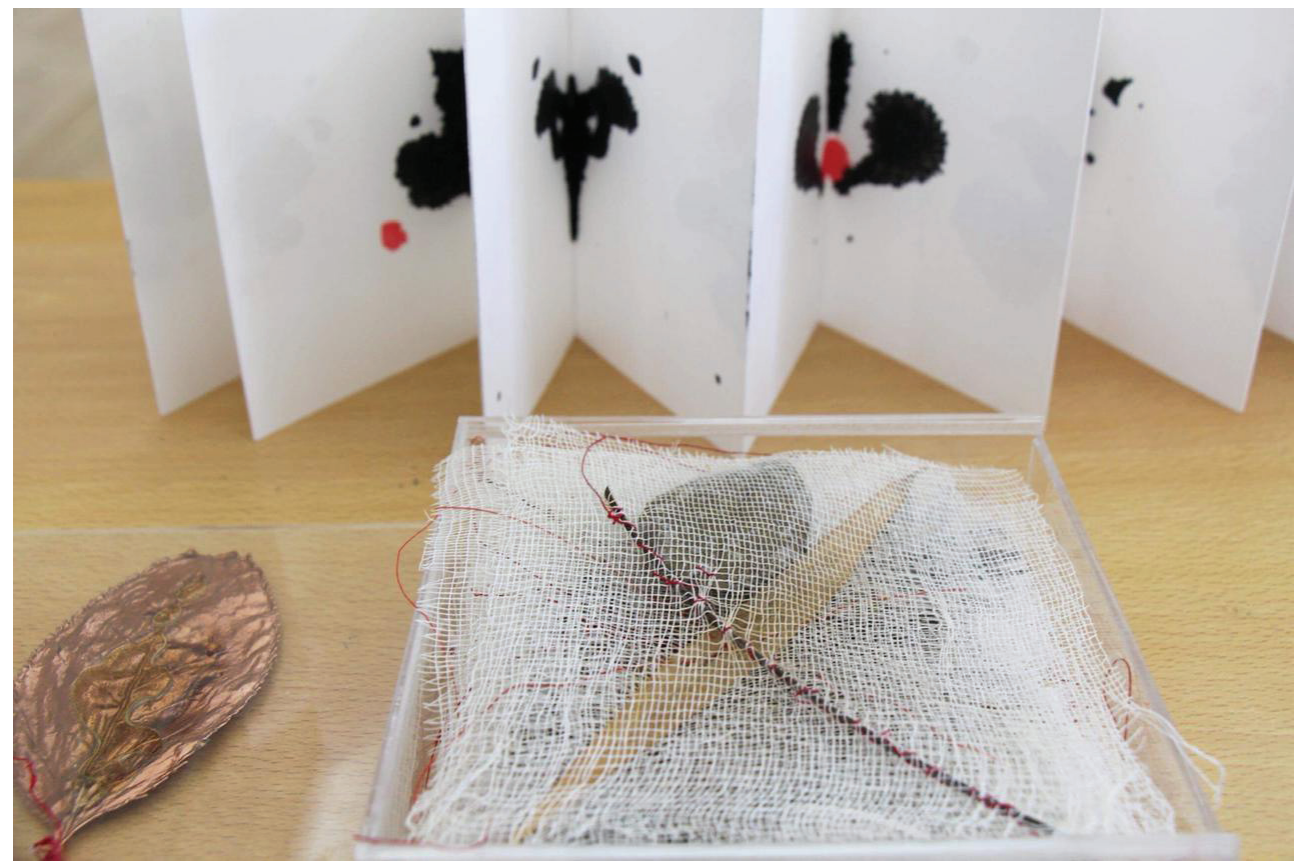

Figura 6 - "Entre folhas". Livro de artista. Folhas de manga rosa e carlota, graviola, tamarindo, mogno, seriguela, erva cidreira, pitanga, goiaba, acerola, gengibre, canela, ouro e cobre e fibras acondicionados em acrílico. $15 \times 15 x-$ $5 \mathrm{~cm}$. Obra que integra o projeto "Feituras e leituras, o livro de artista", setembro de 2018. Cooperativa Árvore. Porto/Portugal. (Arquivo da autora).

Cantos, Contos, Contas: Uma trama às águas como lugar de passagem. Salvador, 2004.

MARTINS, Marcos. Envoltório. 2018. 250 f. Tese de Doutorado. Pós-Graduação em Artes Visuais, Área de Concentração em Poéticas Visuais, Linha de Pesquisa Processos de Criação em Artes Visuais. ECA/USP, São Paulo, 2018.

SALLES, C. A. Gesto inacabado: processo de criação artística. 4 ed. SP: Annablume, 2009.

Redes da Criação: construção da obra de arte - Cecilia Salles. São Paulo: Horizonte/Vinhedo, 2008. 176 p. 